\title{
Aprendizagem do desenho artístico no ensino superior: concepções de estudantes*
}

Luiz Gustavo Lima Freire a António Manuel Duarte ${ }^{b}$

\section{Resumo}

No âmbito da Fenomenografia, este estudo teve como objetivo avaliar a natureza e mapear as concepções de estudantes universitários sobre a aprendizagem do desenho artístico. Um grupo de dezesseis estudantes de uma disciplina livre de desenho foi entrevistado, entre outros aspectos, sobre a natureza, o processo e o contexto da aprendizagem do desenho artístico. As respostas, submetidas a uma análise de conteúdo temática, evidenciaram a distinção entre uma representação da aprendizagem do desenho como algo mais passivo - cópia de realidades observadas; através de técnicas e da prática; no ambiente académico - e algo mais ativo - expressão pessoal; através da compreensão do que se percepciona e de mudanças pessoais; no ambiente amplo. Emergiu também uma representação de meio-termo, que define a aprendizagem do desenho como algo de intermédio - desenvolvimento perceptivo; representação de percepções ou da imaginação; criação de técnicas. A conscientização sobre as concepções de aprendizagem do desenho poderá constituir factor da sua eventual modificação. Assim, a taxonomia que resulta deste estudo poderá ajudar estudantes, professores e técnicos no diagnóstico e intervenção sobre aquele tipo de concepções.

Palavras-chave: Aprendizagem; Avaliação; Concepções; Fenomenografia.

\section{Introdução}

De acordo com a Fenomenografia, a concepção de aprendizagem de um estudante pode ser definida como o significado que ele atribui ao fenômeno

\footnotetext{
* Esta investigação foi desenvolvida no âmbito de um projeto de doutoramento, financiado pela Fundação para a Ciência e a Tecnologia (FCT), através da Bolsa de Investigação SFRH/BD/62430/2009.

a Faculdade dos Guararapes, Recife, PE, Brasil.

b Universidade de Lisboa, Faculdade de Psicologia, Lisboa, Portugal.
} 
da aprendizagem, através do enfoque seletivo em algum ou alguns dos seus múltiplos aspetos (FREIRE; DUARTE, 2010, 2016; MARTON; BOOTH, 1997). As concepções dos estudantes sobre a aprendizagem relacionam-se com outras das suas características pessoais (i.e., cognitivas, afetivas e interpessoais) e com uma diversidade de aspetos ambientais (e.g., objetivos educativos, conteúdos, métodos, materiais e recursos educacionais), influenciando os processos de aprendizagem e os resultados acadêmicos (ASIKAINEN, 2014; HERNÁNDEZ PINA; ROSÁRIO; SÁEZ DE TEJADA, 2010; LEUNG; WONG; WONG, 2013; MARTON; SÄLJÖ, 1976; ROSÁRIO et al., 2014; RUIZ LARA et al., 2011; STEIN; SHEPHARD; HARRIS, 2011; YANG; TSAI, 2010). Em particular, aquelas concepções de aprendizagem tendem a associar-se ao fator mais direto destes resultados, as abordagens dos estudantes à aprendizagem, (ASIKAINEN, 2014; CHEN; TSAI, 2012; VALADAS; GONCALVES; FAISCA, 2011; YANG; TSAI, 2010), pelo que seu diagnóstico e promoção constituem elementos importantes para a compreensão e possibilidade de melhoria do nível de sucesso e de qualidade da aprendizagem (BIGGS, 1990, 2006; SILVA, 2004; MARTON, 1988; SÄLJÖ, 1984).

A investigação tem vindo a atestar a existência de duas formas básicas de os estudantes conceberem o fenômeno da aprendizagem (CHALETA, 2018). Segundo a fenomenografia, uma concepção quantitativa, que vê a aprendizagem como aquisição mecânica de conhecimentos e uma concepção qualitativa, que a toma como compreensão desses conhecimentos (CHAN, 2011; LIN; NIU, 2011).

A concepção quantitativa de aprendizagem representa esta enquanto atividade memorística, como recolha e acumulação mecânica da informação, quando se tem o objetivo de devolver, nas situações de avaliação, o que foi armazenado (BIGGS, 1990, 2006; BIGGS; MOORE, 1993; LAURILLARD, 1979).

Por outro lado, a concepção qualitativa de aprendizagem representa-a como uma atividade estratégica, isto é, baseada na compreensão ou construção do conhecimento, conseguida através de um processo de abstração de significados, da interpretação pessoal da informação e do relacionamento do conhecimento formal, tanto com a realidade como com a experiência (BIGGS, 1989, 1990; BIGGS; MOORE, 1993; BOULTON-LEWIS; WILSS; MUTCH, 1996; CLIFF, 1998; MARTON; BOOTH, 1997).

Complementarmente, as concepções básicas de aprendizagem obedecem a uma diferenciação, que levou à construção de diferentes taxonomias. O sistema mais 
importante é o de Marton, Dall'Alba e Beaty (1993), que diferencia a concepção quantitativa em três concepções específicas (i.e., aprendizagem como aumento de conhecimento; como sua memorização e reprodução; e como sua aplicação) e discrimina a concepção qualitativa em outras três concepções particulares (i.e., aprendizagem como compreensão; como reinterpretação de conhecimento; e como mudança pessoal).

Posteriormente, a investigação na área da fenomenografia propôs ainda a existência de mais três concepções de aprendizagem: a concepção intermediária, que se posiciona entre a quantitativa e a qualitativa, representando a aprendizagem como memorização e compreensão (MARTON; BOOTH, 1997); a concepção comunitária, que encerra a noção de aprendizagem como uma obrigação em relação à comunidade (CLIFF, 1998); e a concepção institucional, que representa a aprendizagem enquanto sucesso acadêmico, assumindo que aprender significa obter o reconhecimento da escola, atestado pelas classificações e o aproveitamento (BIGGS, 1989, 1990; BIGGS; MOORE, 1993; NEWBLE; CLARKE, 1986).

Para além do mais, a investigação fenomenográfica também reflete uma análise fina da variação na concepção de aprendizagem, ao considerar que esta apresenta várias dimensões: dimensão referencial, que se relaciona à natureza da aprendizagem; dimensão processual, que se refere ao processo de aprendizagem; dimensão contextual, que se relaciona à conjuntura da aprendizagem; dimensão funcional, que se refere às consequências ou funções da aprendizagem; e dimensão fatorial, que engloba os fatores aliciadores e inibidores da aprendizagem (ROSE-ADAMS; HEWITT, 2012).

Quase inexistente, a investigação sobre concepções de aprendizagem do desenho é representada por um estudo qualitativo, mas não fenomenográfico, desenvolvido por Cruz et al. (2011), mas com crianças argentinas dos quatro aos seis anos de idade, que permitiu discriminar duas concepções da aprendizagem do desenho figurativo: teoria direta (com duas versões) e teoria interpretativa. Como se verá, essas concepções são similares às descobertas pela fenomenografia, para a aprendizagem em geral. Com efeito, a teoria direta parece-nos equivalente a uma concepção quantitativa de aprendizagem e a teoria interpretativa, a uma concepção qualitativa.

A primeira versão da teoria direta, designada de focalizada nos resultados cumulativos da aprendizagem, caracteriza-se por uma concepção de aprendizagem do desenho enquanto ampliação de resultados gráficos. O produto da aprendizagem 
é concebido como uma realização somativa (saber mais desenhos), sendo que, para alcançá-lo, seriam necessárias apenas atividades básicas e manifestas (desenhar e copiar modelos). A segunda versão da teoria direta, designada de agência do entorno, toma igualmente a aprendizagem do desenho como uma acumulação sumativa, mas articula, em acréscimo, condições e resultados da aprendizagem de acordo com uma lógica linear, ou seja, se as condições se cumprem (e.g., crescimento; saúde; motivação; modelagem do desenho), a aprendizagem, inevitavelmente, ocorre, ao passo que, se a aprendizagem for constatada, terá sido porque as condições foram cumpridas.

Por outro lado, a teoria interpretativa articula os resultados e condições da aprendizagem de acordo com um foco nas representações e processos mentais de quem aprende. $\mathrm{O}$ aprendente se constitui aqui no agente do processo de aprendizagem, não apenas através do exercício da sua atividade observável (desenhar, ver e copiar modelos), ao gerar e ativar suas representações internas (registrar, recordar, antecipar, compreender), como ao exercer a autorregulação sobre as condições e o curso da sua ação (planejar metas, ajustar-se à sua execução, avaliar os próprios resultados e utilizar deliberadamente instrumentos de apoio, como réguas ou modelos). Para essa representação, a aprendizagem faz avançar o modo de desenhar e gera novas representações mentais, enquanto os seus resultados são tidos como mudanças qualitativas em produtos gráficos já conhecidos.

Os resultados aqui apresentados derivam de um estudo que teve como objetivo mapear qualitativamente e explorar quantitativamente as concepções de estudantes universitários sobre a natureza, o processo, os contextos, as causas, as funções e os problemas da aprendizagem do desenho artístico. Com este estudo, esperamos contribuir para aumentar o escasso conhecimento sobre a psicologia da aprendizagem das artes plásticas. Buscamos igualmente ajudar no desenvolvimento de meios de avaliação das concepções de aprendizagem das artes, que possam ajudar a construir modelos de intervenção dirigidos a uma adaptação mais eficaz dos estudantes à universidade.

\section{Método}

Participaram do estudo 16 estudantes de uma universidade brasileira, que cursavam uma disciplina optativa livre de desenho artístico. Nove destes estudantes (56.25\%) eram do sexo masculino e sete $(43.75 \%)$ do feminino, com uma idade média de 22 anos de idade e idades que variavam entre 18 e 28 anos. Três estudantes (18.75\%) eram de um curso de Matemática, 11 (68.75\%) de Ciências Biológicas e dois $(12.50 \%)$ de Letras. A amostragem foi por conveniência, segundo a 
disponibilidade dos estudantes que cursavam a disciplina de desenho artístico, selecionados considerando que a sua experiência de aprendizagem do desenho lhes permitia uma maior articulação das suas concepções sobre esse mesmo tipo de aprendizagem. O critério de determinação da dimensão da amostra foi o da saturação das categorias detectadas pela análise de conteúdo temática (DAUSTER, 2010), realizada às respostas dos participantes à entrevista que serviu como procedimento de recolha dos dados.

A disciplina de desenho artístico, frequentada pelos participantes, possibilita a aprendizagem dos elementos básicos necessários ao desenvolvimento do desenho de criação, incentivando a aplicação correta e sintética da forma, do volume, da proporção, da cor e do equilíbrio numa composição, e habilitando a captar mentalmente uma imagem e transpô-la para uma superfície. Para tanto, o docente oferece exercícios de transposição da imagem para o papel e técnicas de desenho. Entre os conteúdos figuram: o corpo do desenhador (a função da respiração e do olho, a memória corporal, o equilíbrio corporal/gráfico e os membros); o desenho como manifestação criativa (geometrização, sombra, perspectiva, sentimento, deformações dos objetos no desenho e criatividade); e técnicas de desenho.

Previamente à recolha de dados, efetuámos um pedido de permissão às autoridades da universidade e a todos os estudantes da disciplina de desenho artístico, que foram informados da confidencialidade das respostas.

A recolha dos dados foi efetuada por entrevista semiestruturada, realizada individualmente, pré-testada com um estudante e com o docente da disciplina. O guião de entrevista contemplou questões orientadas para as seguintes dimensões da concepção de aprendizagem do desenho artístico: Referencial (Na tua opinião o que é aprender desenho artístico?); Processual (No teu entendimento como se aprende desenho artístico?); Contextual (Na tua apreciação onde se aprende desenho artístico?); Fatorial (No teu entendimento quais são os fatores que influenciam a aprendizagem do desenho artístico?); Funcional (Na tua opinião para que se aprende desenho artístico?); e Problemas (No teu entendimento quais são os problemas que interferem na aprendizagem do desenho artístico?). Devido a limitações de espaço, neste artigo relataremos apenas os resultados encontrados para as três primeiras dimensões. Previu-se ainda que, em acréscimo às questões previstas, fossem articuladas outras, improvisadas no momento da entrevista, tendo em conta o diálogo com os participantes e os objetivos de avaliação para cada dimensão que consta do guião. 
As entrevistas foram realizadas em privado, no recinto da Universidade, tendo sido gravadas em áudio para que pudessem ser transcritas e analisadas posteriormente.

Os dados recolhidos foram sujeitos a uma análise de conteúdo temática que implicou três fases: 1) segmentação das respostas em unidades a categorizar; 2) desenvolvimento e aplicação de um sistema de categorias de análise; 3) exploração das categorias encontradas.

A primeira fase consistiu na segmentação dedutiva dos discursos (respostas dadas pelos estudantes) em unidades a categorizar. Essa segmentação foi efetuada tendo em conta o contexto global das respostas, pois a desconsideração deste poderia favorecer a perda de sentido. Como preconiza o referencial fenomenográfico, todo o conteúdo que remetia ao modo particular de cada um dos estudantes empreender a aprendizagem foi excluído. O critério de segmentação em unidades a categorizar foi o de "segmentação por unidades temáticas" (FLORES, 1994). As respostas foram assim segmentadas, considerando as dimensões das concepções de aprendizagem - ou seja, sempre que uma ideia se referia ao tema de uma das dimensões (Referencial; Processual; Contextual; Fatorial; Funcional; e Problemas) era considerado como uma unidade de análise (a categorizar posteriormente). Deste modo, a segmentação foi dedutiva, visto que se partiu de dimensões consideradas pela teoria e patentes no guião de entrevista. A segmentação das respostas foi efetuada por dois analistas, independentemente, o primeiro autor do estudo e uma psicóloga educacional previamente treinada no procedimento de segmentação. Posteriormente, os analistas realizaram uma comparação da segmentação efetuada, com o objetivo de identificar e resolver, por discussão, possíveis discordâncias.

A segunda fase da análise dos dados consistiu na construção e aplicação de um sistema de categorias de análise, para categorização das unidades anteriormente segmentadas. O sistema de categorização foi desenvolvido, como preconiza o referencial fenomenográfico, de acordo com uma abordagem indutiva (MILES; HUBERMAN, 1994), ou seja, as categorias emergiam na medida em que iam sendo detectadas, sem a utilização de classes de análise pré-existentes. A prática da categorização começou com a codificação das unidades, previamente segmentadas, de aproximadamente $20 \%$ das entrevistas. Esse trabalho, que foi desenvolvido de forma independente pelos dois juízes (após a introdução do procedimento de categorização ao segundo), teve como resultado a construção de uma primeira grelha de análise, alterada após a revisão de um especialista em Fenomenografia (o segundo autor deste estudo) quanto à sua lógica interna. A grelha resultante foi, então, utilizada de forma 
independente pelos dois juízes, para categorização das unidades das demais entrevistas, ou seja, em aproximadamente $80 \%$ delas. Durante essa fase, a análise passou a valer-se da utilização daquela primeira versão da grelha, mas esteve aberta ao aparecimento de novas categorias. Esse processo teve como resultado a construção de uma segunda grelha, alterada após revisão da sua lógica interna, pelo segundo autor. Finalmente, a segunda grelha de análise (que coincide com o sistema de categorias apresentado na seção dos Resultados) foi utilizada independentemente pelos dois juízes, para nova categorização das unidades da totalidade das entrevistas. As categorias foram organizadas em metacategorias (agrupamento de categorias), categorias e subcategorias (fracionamento de categorias), de acordo com a natureza hierárquica das concepções de aprendizagem encontradas. A avaliação da confiança do sistema de categorização foi efetuada através da comparação interjuízes, calculado na base do procedimento proposto por Bakeman e Gottman (1986) 1 . O acordo foi de $100 \%$ para a dimensão Referencial e para a dimensão Contextual e de $84.7 \%$ para a dimensão Processual, com uma média de $94.9 \%$. De forma a ficar com um registo das concepções de aprendizagem correspondentes a cada participante, os desacordos entre juízes foram resolvidos por consenso através de discussão. Mais tarde, foi também calculado o acordo intrajuiz (96.6\%), onde o primeiro juiz realizou uma nova categorização de $12.5 \%$ dos segmentos das respostas.

A terceira fase da análise dos dados consistiu no exame da representatividade das categorias e metacategorias na amostra de participantes, através do cálculo da frequência relativa em que cada uma daquelas emerge. Para tal, a presença de cada categoria foi contada como uma incidência, independentemente do número de vezes em que está presente no discurso de cada um dos participantes.

\section{Resultados}

\subsection{Dimensão Referencial - O que é aprender desenho artístico}

Identificámos, para além de uma concepção vaga (apresentada por $18.7 \%$ dos participantes), onde não há uma noção clara do que é a aprendizagem do desenho, três representações básicas de complexidade crescente (meta-categorias) que designámos de Passiva, Intermédia e Ativa.

A concepção Passiva (apresentada por $62.5 \%$ dos participantes), equivale a uma representação da aprendizagem do desenho como o desenvolvimento de uma

$\mathrm{PA}=(\mathrm{Na} /(\mathrm{Na}+\mathrm{Nd})) 100$, em que "PA" é a percentagem de acordo; "Na" é a frequência de acordo e "Nd" é a frequência dos desacordos. 
competência que se limita à observação e representação de realidades externas observadas. Essa concepção expressa-se em duas variantes. A mais simples, designada de Transcrever o que se vê (em $62.5 \%$ dos participantes), defende que a aprendizagem do desenho consiste no desenvolvimento da competência de transcrever/deslocar/copiar algo que se vê para uma superfície, através do desenho (e.g., "(...) transcrever uma coisa que você vê, passar (...) para alguma superfície (...)"). A variante mais elaborada, designada de Representar o que se vê (em $25 \%$ dos participantes), vai um pouco mais longe, ao defender que aprendizagem do desenho consiste no desenvolvimento da competência de representar numa superfície algo que se vê (e.g., (...) representar algo que a gente esteja vendo (...)").

A concepção Intermédia (apresentada por $50 \%$ dos participantes), um pouco mais sofisticada, corresponde a uma representação da aprendizagem do desenho como meio caminho entre a concepção passiva e a ativa, centrando-a em torno da percepção de realidades externas ou imaginadas. Essa concepção manifesta-se em três variantes. A variante mais simples, designada de Transcrever/representar o que se percebe (em 12.5\% dos participantes), defende que a aprendizagem do desenho consiste no desenvolvimento da competência de transcrever/ deslocar algo que se percepciona para uma superfície, através do desenho (e.g., “(...) perceber o espaço (...) as pessoas (...) o movimento em si e conseguir reproduzir (...)"). Uma outra variante, designada de Transcrever/representar o que se imagina (em 18.7\% dos participantes), admite que a aprendizagem do desenho consiste no desenvolvimento da competência de transcrever/deslocar algo que se imagina para uma superfície, através do desenho (e.g., “(...) é colocar no papel, através da imagem, (...) coisas imaginárias (...)"). Por seu lado, a variante mais elaborada, designada de Mudar a percepção (em 25\% dos participantes), reconhece a aprendizagem do desenho como o desenvolvimento/ aprofundamento da percepção visual (e.g., “(...) é (...) uma nova maneira de enxergar (...) observar detalhes (...) enxergar (...) a um nível que no quotidiano você não consegue (...) enxergar (...) profundidade (...)".

Finalmente, a concepção Ativa (apresentada por $37.5 \%$ dos participantes), a mais elaborada, equivale a uma representação da aprendizagem do desenho como expressão pessoal. Designada de Expressar o que se sente, essa concepção assume a aprendizagem do desenho como o desenvolvimento da competência para expressar o que se sente (e.g., “(...) é uma forma (...) de expressar (...) sentimento (...)”).

Na tabela 1 é possível consultar uma síntese dos resultados relativos à dimensão referencial. 
Tabela 1. Dimensão Referencial - O que é aprender desenho artístico

\begin{tabular}{|c|c|c|c|}
\hline Metacategoria & $\%$ & Categoria & $\%$ \\
\hline Vaga & 18.7 & Vaga & 18.7 \\
\hline \multirow{2}{*}{ Passiva } & \multirow{2}{*}{62.5} & Transcrever o que se vê & 62.5 \\
\hline & & Representar o que se vê & 25 \\
\hline \multirow{3}{*}{ Intermédia } & \multirow{3}{*}{50} & Transcrever/representar o que se percebe & 12.5 \\
\hline & & Transcrever/representar o que se imagina & 18.7 \\
\hline & & Mudar a percepção & 25 \\
\hline Ativa & 37.5 & Expressar o que se sente & 37.5 \\
\hline
\end{tabular}

Fonte: dados da pesquisa (2017).

\subsection{Dimensão processual - como se aprende desenho artístico}

Identificámos, para além de uma concepção vaga (apresentada por $6.2 \%$ dos participantes), onde não há uma noção clara de como ocorre a aprendizagem do desenho, três representações básicas daquele processo de aprendizagem (meta-categorias), de complexidade crescente, que designamos igualmente de Passiva, Intermédia e Ativa.

A concepção Passiva (apresentada por 100\% dos participantes), equivale a uma representação do processo de aprendizagem do desenho como um processo observacional e operativo. Expressa-se em cinco variantes. A primeira, e mais elementar, designada de Observando (em 31.2\% dos participantes), defende que se aprende desenho observando os objetos ou os seus elementos constitutivos (e.g., “(...) através da visão (...) observando (...) detalhes (...) ter uma visão (...) detalhada das coisas (...)"). A segunda, denominada Praticando (em 75\% dos participantes), admite que se aprende desenho praticando (e.g., “(...) na prática (...) se aprende desenho desenhando, praticando, exercitando (...)"). A terceira, nomeada Utilizando técnicas (em $68.7 \%$ dos participantes), reconhece que se aprende desenho adquirindo e utilizando técnicas (e.g., “(...) com técnicas (...) através de técnicas (...)"). A quarta, designada de Transcrevendo o que se observa (em $12.5 \%$ dos participantes), assume que se aprende desenho desenvolvendo a competência de transcrever/deslocar/copiar algo que se observa para uma superfície (e.g., “(...) ele olha (...) reproduz (...) é conseguir colocar no papel a realidade (...) você observa (...) o (...) que (...) quer desenhar (...)"). A quinta, e mais elaborada, denominada Representando o que se observa (em $6.2 \%$ dos participantes), defende que se aprende desenho desenvolvendo a competência 
de representar numa superfície algo que se observa (e.g., “(...) com uma pessoa que (...) ensine como representar aquilo que você está vendo (...)”).

A concepção Intermédia (apresentada por $18.7 \%$ dos participantes), um pouco mais refinada, corresponde a uma representação do processo de aprendizagem do desenho como um processo perceptivo, representativo e criativo. Essa concepção revela-se em duas variantes. A primeira, designada de Transcrevendo o que se percebe (em $6.2 \%$ dos participantes), reconhece que se aprende desenho desenvolvendo a competência de transcrever/deslocar algo que se percepciona para uma superfície (e.g., “(...) perceber de forma (...) sensível (...) passar (...) um desenho (...)"). A segunda, denominada Criando técnicas (em 12.5\% dos participantes), assume que se aprende desenho desenvolvendo novas técnicas (e.g., “(...) você (...) talvez (...) crie outras técnicas (...) criar uma outra forma (...) você mesmo pode construir (...)").

Finalmente, a concepção Ativa (apresentada por 37.5\% dos participantes), a mais aprimorada, equivale a uma representação do processo de aprendizagem do desenho como um processo compreensivo e transformativo. Expressa-se em duas variantes. A primeira, designada Compreendendo o que se observa (em 31.2\% dos participantes), defende que se aprende desenho desenvolvendo a competência de compreender (entender) o que se vê (e.g., “(...) você tem que ter (...) poder de abstração (...) para colocar aquilo no papel (...) se não parasse para analisar (...) como é que (...) ia desenhar? (...)"). A segunda, nomeada Mudando (em 6.2\% dos participantes), admite que se aprende desenho modificando a sensibilidade pessoal e/ou transfigurando o que se percepciona (e.g., “(...) quando a gente está aprendendo (...) modifica (...) a realidade (...) a pessoa que está (...) aprendendo (...) também é modificada (...) sua sensibilidade (...) é aguçada, ela começa a ver as coisas de forma diferente (...)").

Na tabela 2 é possível consultar uma síntese dos resultados relativos à dimensão processual.

\subsection{Dimensão contextual - onde se aprende desenho artístico}

Identificámos, em terceiro lugar, duas representações básicas (meta-categorias) sobre o contexto da aprendizagem do desenho, designadas de Contexto espacial e Contexto social. A primeira dessas concepções (apresentada por 100\% dos participantes), expressa-se em duas variantes. A primeira das variantes, menos abrangente, designada de Contexto Acadêmico (em 6.2\% dos participantes), defende que a aprendizagem do desenho se realiza no ambiente institucional da 
Tabela 2. Dimensão Processual - Como se aprende desenho artístico

\begin{tabular}{lccc}
\hline Metacategoria & $\%$ & Categoria & $\%$ \\
\hline Vaga & 6.2 & Vaga & 6.2 \\
& & Observando & 31.2 \\
& \multirow{2}{*}{100} & Praticando & 75 \\
Passiva & & Utilizando técnicas & 68.7 \\
& & Transcrevendo o que se observa & 12.5 \\
& \multirow{2}{*}{18.7} & Representando o que se observa & 6.2 \\
Intermédia & & Transcrevendo o que se percebe & 6.2 \\
& \multirow{2}{*}{37.5} & Criando técnicas & 12.5 \\
Ativa & & Compreendendo o que se observa & 31.2 \\
& & Mudando & 6.2 \\
\hline
\end{tabular}

Fonte: dados da pesquisa (2017).

escola (e.g., “(...) na academia (...) universidade (...)”). A segunda das variantes, mais abrangente, nomeada Contexto Alargado (em 93.7\% dos participantes), assume que a aprendizagem do desenho ocorre no meio ambiente em geral (e.g., “(...) em qualquer lugar (...)”).

A segunda meta-categoria, Contexto social (apresentada por $56.2 \%$ dos participantes), expressa-se igualmente em duas variantes. A primeira variante, denominada Com apoio (apresentada por 31.2\% dos participantes), representa a aprendizagem do desenho como algo dependente do apoio externo de alguém e compreende duas subvariantes: a) Do professor (em 43.7\% dos participantes), que reconhece que se aprende desenho com o auxílio de um docente (e.g., "(...) tendo algum professor (...) que ensine (...)”); e b) Dos outros (em 18.7\% dos participantes), que admite que se aprende com a ajuda de outros indivíduos que não o professor (e.g., "(...) com alguém que já saiba (...)"). A segunda variante da metacategoria Contexto Social, designada Autonomamente (em 31.2\% dos participantes), assume a aprendizagem do desenho como algo que se pode realizar autonomamente, sem apoio externo (e.g., “(...) pode ser sozinho (...)”).

Na tabela 3 é possível consultar uma síntese dos resultados relativos à dimensão contextual.

Atendendo à generalidade dos resultados, podemos constatar a presença de duas representações básicas e, aparentemente, opostas sobre a aprendizagem 
Tabela 3. Dimensão Contextual - Aonde se aprende desenho artístico

\begin{tabular}{lccccc}
\hline Meta-categoria & $\%$ & Categoria & $\%$ & Subvariante & $\%$ \\
\hline \multirow{2}{*}{ Contexto espacial } & \multirow{2}{*}{100} & Académico & 6.2 & - & - \\
& & Alargado & 93.7 & - & - \\
\multirow{2}{*}{ Contexto social } & \multirow{2}{*}{56.2} & Com apoio & 31.2 & a) com professor & 43.7 \\
& & Autonomamente & 31.2 & b) com outros & 18.7 \\
\hline
\end{tabular}

Fonte: dados da pesquisa (2017).

do desenho. Por um lado, uma concepção dessa aprendizagem como algo mais limitado ou mais passivo (i.e., relacionado à cópia ou quanto muito à representação de realidades observadas; através de técnicas e da prática; num contexto académico). Por outro, uma representação da aprendizagem do desenho como algo mais aberto ou mais ativo (i.e., relativo à expressão pessoal; através da compreensão do que se percepciona e de mudanças pessoais; no contexto do ambiente amplo). Complementarmente, considerando apenas as dimensões Referencial e Processual da concepção de aprendizagem (as nucleares), registou-se uma outra representação básica, de aparente meio-termo em relação a essas duas, que define a aprendizagem do desenho como algo de intermédio (i.e., desenvolvimento perceptivo; representação de percepções ou da imaginação; criação de técnicas).

\section{Discussão}

Considerando os resultados em geral, diríamos que a dicotomia básica encontrada entre uma Concepção Passiva e uma Concepção Ativa da aprendizagem do desenho parece-nos um eco da dicotomia tipicamente encontrada pelos estudos fenomenográficos sobre a concepção de aprendizagem em geral, entre uma concepção Quantitativa de aprendizagem (i.e., enquanto memorização passiva, no contexto académico) e uma concepção Qualitativa de aprendizagem (i.e., enquanto compreensão, no ambiente amplo) (MARTON; DALL'ALBA; BEATY, 1993). Para além disso, a concepção Intermédia de aprendizagem do desenho encontrada parece-nos em parte isomorfa a uma concepção Intermédia de aprendizagem em geral (i.e., enquanto memorização e compreensão). Observa-se, assim, uma replicação da conhecida hierarquia de noções sobre a aprendizagem em geral (i.e., de uma noção Quantitativa para uma Qualitativa, passando por uma Intermédia). Essa variação, possivelmente, reflete uma progressão desenvolvimentista, ou evolutiva, das ideias sobre a aprendizagem do desenho. A aprendizagem formal do desenho 
provavelmente começará por envolver a aquisição e prática académica de técnicas de representação do que se observa antes de se transformar no desenvolvimento criativo da representação da percepção e imaginação e, finalmente, no domínio da expressão pessoal. O paralelismo encontrado entre a concepção de aprendizagem do desenho e da concepção de aprendizagem geral sugere que essa se constitui tanto quanto reflexo como quanto fator da diversidade de dicotomias específicas das concepções de aprendizagem em domínios particulares, como o aqui investigado.

Consideremos especificamente, em primeiro lugar, os resultados da dimensão Referencial da concepção de aprendizagem do desenho.

A concepção vaga (18.7\%), é similar à concepção Vaga sobre a aprendizagem em geral (FREIRE; DUARTE, 2010) e pode explicar-se pela possível ausência de uma aprofundada reflexão anterior, por parte dos participantes, acerca da natureza da aprendizagem do desenho. Essa aprendizagem pode estar sendo representada de forma tácita e não diferenciada, acompanhando um processo de aprendizagem eventualmente mais automático e não consciente.

As três representações básicas de complexidade crescente sobre a aprendizagem do desenho (i.e., Passiva, Intermédia e Ativa) são similares, respectivamente, à concepção quantitativa, intermédia e qualitativa de aprendizagem em geral (DUARTE, 2002) e podem explicar-se pela existência de uma possível sofisticação progressiva da representação da aprendizagem do desenho, eventualmente radicada na possível diferenciação de crenças epistemológicas sobre o desenho.

A concepção Passiva (62.5\%) é similar à concepção Quantitativa de aprendizagem em geral, onde esta é tida como ampliação de informação existente. A sua variante mais simples (i.e., Transcrever o que se vê - 62.5\%) é similar à concepção Memorização e reprodução de aprendizagem geral (MARTON; DALL'ALBA; BEATY, 1993) e à concepção Ver e copiar modelos, desvendada noutro enquadramento teórico, por Cruz et al. (2011) e pode explicar-se pela própria natureza da atividade do desenho, que envolverá construir uma imagem mental a partir de uma realidade e transpô-la da mente para um material. Mas, embora pareça tratar-se aqui de uma concepção acumulativa, é de marcar uma nuance particular, uma vez que ver pode não ser necessariamente representado como uma captação objetiva, mas como algo afetado pelos sentidos e pela subjetividade com ênfase para o papel da memória visual e do desempenho motor no processo de aprendizagem do desenho. A variante mais elaborada da concepção Passiva (i.e., Representar 
o que se vê - 25\%) pode ser considerada similar à concepção Memorização e aplicação da aprendizagem geral (MARTON; DALL'ALBA; BEATY,1993), se considerarmos a representação como equivalente à aplicação, no sentido em que também envolve um processo de adaptação.

A concepção Intermédia (50\%) é similar à concepção Intermédia da aprendizagem em geral (DUARTE, 2002) e pode tomar-se como a generalização, nesse domínio, da ideia mais geral da aprendizagem como conjugação da memorização com a compreensão. A concepção Intermédia da aprendizagem do desenho pode explicar-se pela consciência dessa como um processo que provavelmente envolve o domínio da integração da percepção de uma realidade exterior (i.e., primeira variante - Transcrever/representar o que se percebe $-12.5 \%$ ) ou da percepção de uma realidade interna (i.e., segunda variante -Transcrever/representar o que se imagina $-18.7 \%$ ) com a competência de trasladar para um suporte (e.g., o papel) o resultado dessa percepção. Por outro lado, a variante mais elaborada da concepção Intermédia (i.e., Mudar a percepção - 25\%) parece-nos similar à concepção Reinterpretação da aprendizagem em geral (MARTON; DALL'ALBA; BEATY, 1993), podendo refletir a consciência de que a aprendizagem do desenho é talvez, em grande parte, uma aprendizagem da observação, ou seja, uma mudança da forma como se percepciona a realidade.

Finalmente, a concepção Ativa - Expressar o que se sente (37.5\%) parece-nos a mais similar à concepção qualitativa da aprendizagem em geral, na medida em que em alternativa a uma noção daquela aprendizagem como domínio da competência de captar ou percepcionar e representar a realidade, enfatiza o domínio da competência (provavelmente envolvida em fases mais avançadas da aprendizagem do desenho) de ser sensível, ou ser capaz de alocar uma interpretação, ao carácter expressivo da realidade observada (ou às reações sensoriais e emocionais que ela provoca), assim como de ser capaz de "materializar", ou expressar, essas sensações e emoções.

Consideremos especificamente, de seguida, os resultados relativos à dimensão Processual da concepção de aprendizagem do desenho.

A concepção Vaga (6.2\%) é similar à concepção Vaga sobre a aprendizagem em geral (FREIRE; DUARTE, 2010) e pode explicar-se pela provável ausência de uma reflexão por parte dos participantes acerca do processo da aprendizagem do desenho. Com efeito, esse pode estar sendo representado de forma tácita e não diferenciada, ou automática e não consciente. 
A concepção Passiva (100\%) é similar à concepção quantitativa de aprendizagem em geral (FREIRE; DUARTE, 2010) e poderá ser explicada pelo fato dos participantes se encontrarem, à altura da entrevista, numa fase de iniciação ao desenho, provavelmente mais significativa em termos da aquisição de competências de observação e transcrição, do que de expressão, eventualmente mais típica de uma fase avançada. A primeira variante da concepção Passiva - a concepção Observando (43.7\%), é similar à concepção Observando sobre a aprendizagem em geral (FREIRE; DUARTE, 2010) e pode explicar-se pela importância que a observação visual possuirá na aprendizagem do desenho. A segunda variante da concepção Passiva - a concepção Praticando (75\%), não parece encontrar correspondência na literatura sobre a concepção de aprendizagem em geral e pode explicar-se pela importância que a prática terá na aprendizagem do desenho, considerando que envolverá o desenvolvimento de competências e hábitos sensório-motores. A terceira variante da concepção Passiva - a concepção Utilizando técnicas (68.7\%), não parece encontrar correspondência na literatura sobre a concepção de aprendizagem em geral e pode explicar-se pela natureza da aprendizagem do desenho, que implicará a aquisição de uma diversidade de técnicas. A quarta variante da concepção Passiva - a concepção Transcrevendo o que se observa (12.5\%), é similar à concepção de aprendizagem em geral Reproduzindo (MARTON; DALL'ALBA; BEATY, 1993) e pode explicar-se pela necessidade, a que o desenho obrigará, de criar marcas num suporte gráfico com base numa observação. A quinta variante da concepção Passiva - a concepção Representando o que se observa (6.2\%), não parece encontrar correspondência na literatura sobre a concepção de aprendizagem em geral e pode explicar-se pela necessidade das marcas desenhadas constituírem signos que remetam para e traduzam a realidade observada.

A concepção Intermédia (18.7\%) é similar à concepção Intermédia de aprendizagem em geral (MARTON; BOOTH, 1997) e poderá ser explicada pela utilização da memorização como um complemento à compreensão na aprendizagem em questão. Ou seja, na medida em que a memorização retém o "significado" das "mensagens" compreendidas (do modelo ou objeto a ser desenhado) ela poderá permitir a "aplicação" desse "conhecimento" a um novo "contexto" (nesse caso, o papel). A primeira variante da concepção Intermédia - a concepção Transcrevendo o que se percebe (6.2\%) é similar à concepção intermédia da aprendizagem em geral (MARTON; BOOTH, 1997) e pode explicar-se pela percepção de que o desenho envolverá a integração de processos de observação compreensiva com processos de representação técnica do que se observa. A segunda variante da concepção Intermédia - a concepção Criando técnicas (12.5\%), parece similar à concepção Reinterpretando da aprendizagem 
em geral (MARTON et al., 1993) e pode explicar-se pela possível necessidade de variabilidade executiva da prática do desenho, que poderá levar à criação de técnicas de representação.

A concepção Ativa (37.5\%) é similar à concepção qualitativa de aprendizagem em geral (FREIRE; DUARTE, 2010) e poderá ser explicada pela necessidade de o indivíduo compreender ou desenvolver significados pessoais através do desenho. A primeira variante da concepção Ativa - a concepção Compreendendo o que se observa $(31,2 \%)$ é similar à concepção compreendendo da aprendizagem em geral (MARTON; DALL'ALBA; BEATY, 1993) e pode explicar-se como resultado de que observar um objeto que deverá ser desenhado poderá implicar interpretar esse mesmo objeto. Finalmente, a segunda variante da concepção Ativa - a concepção Mudando (6.2\%) é similar à concepção Mudando, da aprendizagem em geral (MARTON; DALL'ALBA; BEATY, 1993) e pode explicar-se pela consequência que a aprendizagem do desenho terá no modo de ver o mundo e a si mesmo.

Consideremos, especificamente, por fim, os resultados relativos à dimensão Contextual da concepção de aprendizagem do desenho.

A concepção Acadêmico (6.2\%) é similar à concepção Restrita, da aprendizagem em geral (FREIRE; DUARTE, 2010) e pode explicar-se pela percepção de que a aprendizagem do desenho obrigará a uma estruturação formal dos conceitos e da metodologia adequada ao desenvolvimento da habilidade de representação gráfica, que carenciará do ensino escolar.

A concepção Alargado (93.7\%) é similar à concepção Ampla, da aprendizagem em geral (FREIRE; DUARTE, 2010) e pode explicar-se pelo entendimento de que o desenvolvimento da competência de desenhar exige que se ultrapasse os limites da escola, eventualmente através da prática e do contato com outros modelos (e.g., museus).

A concepção Com apoio (31.2\%), pode explicar-se pela percepção de que o domínio do desenho deriva do domínio das habilidades motoras e perceptivas que podem ser treinadas e ensinadas por um professor.

A concepção Autonomamente (31.2\%) pode explicar-se pela percepção de que desenhar é um dom, um talento de que somente alguns desfrutam ou, em alternativa, pela percepção de que a aprendizagem do desenho se poderá realizar de forma autodirigida e eventualmente autorregulada. 
Concluindo, aponte-se que uma das limitações deste estudo se relacionou com alguma dificuldade apresentada pelos entrevistados em responderem às questões da entrevista, o que, possivelmente, ocorreu em função de, até aquele momento, não terem refletido sistematicamente acerca das suas concepções de aprendizagem do desenho. Para além disso, derivando de um estudo qualitativo e exploratório, os resultados não podem (nem pretendem) ser generalizados para a população, mas robustecem a teoria fenomenográfica.

A conscientização dos estudantes sobre as suas concepções de aprendizagem do desenho, poderá constituir um factor da sua eventual modificação. Nesse sentido, a taxonomia que resulta deste estudo poderá ajudar estudantes, professores e outros técnicos no diagnóstico e intervenção sobre aquele tipo de concepção

Finalmente, emergem diferentes linha de investigação futura com base neste estudo. Em primeiro lugar, o estudo sugere a possibilidade de construção de um questionário sobre concepções de aprendizagem do desenho, que permita uma avaliação quantitativa com amostras de maior dimensão. Em segundo lugar, o estudo sugere pesquisas que tanto testem uma possível progressão das concepções de aprendizagem do desenho em função do avanço acadêmico, como investiguem a forma como elas se relacionam com outras variáveis (e.g., as abordagens à aprendizagem do desenho; a epistemologia pessoal sobre o desenho; a concepção de aprendizagem de desenho dos professores). Em último lugar, o estudo sugere investigações que permitam testar o efeito de intervenções orientadas para ajudar os estudantes a tomarem consciência das suas concepções de aprendizagem do desenho e eventualmente as modificarem. 


\section{Learning of artistic drawing in higher education: conceptions of students}

\section{Abstract}

In the scope of Phenomenography, this study had as objective to evaluate and map university students' conceptions on learning artistic drawing. A group of sixteen students from a free drawing course was interviewed, among other aspects, on the nature, the process and the context of learning artistic drawing. The answers, submitted to a thematic analysis, showed the distinction between a representation of that learning as something more passive - copying observed realities through techniques and practice; in the academic environment - and something more active - personal expression through the understanding of what is perceived and of personal changes, in a broader environment. A middle-term representation also emerged, which defines learning of drawing as something intermediary - perceptual development, representation of perceptions or of imagination, creation of techniques. Awareness of conceptions of learning drawing might be a possible modification factor of those conceptions. Thus, the taxonomy that results from this study can help students, teachers and technicians in the diagnosis and intervention on that type of conception.

Keywords: Conceptions; Evaluation; Learning; Phenomenography.

\section{Aprendizaje del dibujo artístico en la enseñanza superior: concepciones de estudiantes}

\section{Resumen}

En el marco de la Fenomenografia, este estudio tuvo como objetivo evaluar y mapear las concepciones de estudiantes universitarios sobre el aprendizaje del dibujo artístico. Un grupo de dieciséis estudiantes de una disciplina libre de dibujo fue entrevistado, entre otros aspectos, sobre la naturaleza, el proceso y el contexto del aprendizaje del dibujo artístico. Las respuestas, sometidas a un análisis de contenido temático, evidenciaron la distinción entre una representación del aprendizaje del dibujo como algo más pasivo - copia de realidades observadas; a través de técnicas y de la práctica; en el ambiente académico - y algo más activo - expresión personal; a través de la comprensión de lo que se percibe y de cambios personales; en el ambiente amplio. También surgió una representación de medio término, que define el aprendizaje del dibujo como algo de intermedio - desarrollo perceptivo; representación de percepciones o de la imaginación; creación de técnicas. La concientización sobre las concepciones de aprendizaje del dibujo artístico puede constituir un factor de su eventual modificación. Así, la taxonomía que resulta de este estudio podrá ayudar a estudiantes, profesores y técnicos en el diagnóstico e intervención sobre ese tipo de concepción.

Palabras clave: Aprendizaje; Evaluación; Concepciones, Fenomenografía. 


\section{Referências}

ASIKAINEN, H. Successful learning and studying in biosciences: exploring how students' conceptions of learning, approaches to learning, motivation and their experiences of the teaching-learning environment are related to study success. 2014. 103f. Tese (Doutorado em Ciências da Educação) - Universidade de Helsinki, Helsinki, Finlândia, 2014.

BAKEMAN, R.; GOTTMAN, J. M. Observing interaction: an introduction to sequential analysis. Cambridge: Cambridge University, 1997.

BIGGS, J. B. Approaches to the enhancement of tertiary teaching. Higher education research and development, v. 8, n. 1, p. 7-25, 1989. https://doi.org/10.1080/0729436890080102

. Teaching for desired learning outcomes. In: ENTWISTLE, N. (Org.). Handbook of educational ideas and practices. London: Routledge, 1990. p. 681-93.

. Calidad del aprendizaje universitario. Madrid: Narcea, 2006.

BIGGS, J. B.; MOORE, P. The process of learning. 3. ed. Sydney: Prentice Hall, 1993.

BOULTON-LEWIS, G. M.; WILSS, L.. MUTCH, S. Teachers as adult learners: their knowledge of their own learning and implications for teaching. Higher Education, v. 32, n. 1, p. 89-106, 1996. https://doi. org/10.1007/BF00139220

CHALETA, M. E. Concepções de aprendizagem em estudantes do ensino superior: reanálise do COLI (inventário de concepções de aprendizagem). Ensaio: Avaliação e Políticas Públicas em Educação, Rio de Janeiro, v. 26, n. 100, p. 684-705, 2018. https://doi.org/10.1590/s010440362018002601302.

CHAN, K.-W. Preservice teacher education students' epistemological beliefs and conceptions about learning. Instructional Science, v. 39, n. 1, p. 87-108, 2011. https://doi.org/10.1007/s11251-009-9101-1

CLIFF, A. F. Teacher-learners' conceptions of learning: evidence of a "communalist" conception amongst postgraduate learners? Higher Education, v. 35, n. 2, p. 205-20, 1998. https://doi.org/10.1023/A:1003021132510 
CRUZ, M. et al. Las concepciones de los niños acerca del aprendizaje del dibujo como teorías implícitas. In: SCHEUER, N. et al. (Coords.). Nuevas formas de pensar la enseñanza y el aprendizaje: las concepciones de profesores y alumnos. Barcelona: Graó, 2011. p. 135-51.

DAUSTER, T. Navegando contra a corrente? o educador, a antropólogo e o relativismo. In: BRANDÃO, Z. (Org.). A crise dos paradigmas e a educação. São Paulo, SP: Cortez, 2010.

DUARTE, A. M. Aprendizagem, ensino e aconselhamento educacional: uma perspectiva cognitivo-motivacional. Porto: Porto, 2002.

FLORES, J. Análisis de datos cualitativos: aplicaciones a la investigación educativa. Barcelona: Promociones y Publicaciones Universitarias, 1994.

FREIRE, L. G.; DUARTE, A. M. Concepções de estudantes universitários brasileiros sobre os fatores e as funções da aprendizagem. Ensaio: Avaliação e Políticas Públicas em Educação, Rio de Janeiro, v. 24, n. 91, 2016. https://doi.org/10.1590/S0104-40362016000200006

FREIRE, G. L.; DUARTE, A. M. Concepções de aprendizagem em estudantes universitários brasileiros. Psicologia USP, São Paulo, v. 21, n. 4, p. 875-98, 2010. https://doi.org/10.1590/S0103-65642010000400012

HERNÁNDEZ PINA, F.; ROSÁRIO, P. J. S. L. F. SÁEZ DE TEJADA, J. D. C. Impacto de un programa de autorregulación del aprendizaje en estudiantes de Grado. Revista de Educación, n. 353, p. 571-88, 2010.

LAURILLARD, D. The processes of student learning. Higher education, v. 8, n. 4, p. 395-409, 1979. https://doi.org/10.1007/BF01680527

LEUNG, C.-H.; WONG, B. K.-M.; WONG, J. Conceptions of learning in pre-service and in-service early childhood education students and the impact of teaching experience. Australasian Journal of Early Childhood, v. 38, n. 3, p. 57, 2013.

LIN, H.-M.; NIU, H.-J. A phenomenographic approach for exploring learning marketing conceptions of undergraduate students. Business and Economic Research, v. 1, n. 1, p. 1-12, 2011.

MARTON, F. Describing and improving learning. Learning Strategies and Learning Styles, v. 53, p. 53-82, 1988. https://doi.org/10.1007/978-1-48992118-5_3 
MARTON, F.; BOOTH, S. Learning and awareness. Mahwah: Lawrence Erlbaum, 1997.

MARTON, F.; DALL'ALBA, G.; BEATY, E. Conceptions of learning. International Journal of Educational Research, v. 19, n. 3, p. 277-300, 1993.

MARTON, F.; SÄLJÖ, R. On qualitative differences in learning: I outcome and process. British Journal of Educational Psychology, v. 46, n. 1, p. 4-11, 1976. https://doi.org/10.1111/j.2044-8279.1976.tb02980.x

MILES, M. B.; HUBERMAN, A. M. Qualitative data analysis: an expanded sourcebook. Thousand Oaks, CA: Sage, 1994.

NEWBLE, D. I.; CLARKE, R. The approaches to learning of students in a traditional and in an innovative problem-based medical school. Medical Education, v. 20, n. 4, p. 267-73, 1986. https://doi.org/10.1111/j.1365-2923.1986.tb01365.x

ROSÁRIO, P. et al. Understanding gypsy children's conceptions of learning: a phenomenographic study. School Psychology International, v. 35, n. 2, p. 152-66, 2014. https://doi.org/10.1177/0143034312469304

ROSE-ADAMS, J.; HEWITT, L. 'What retention'means to me: the position of the adult learner in student retention. Widening Participation and Lifelong Learning, v. 14, p. 146-64, 2012. https://doi.org/10.5456/WPLL.14.S.146

RUIZ LARA, E. et al. Metas, concepciones educativas y enfoques de aprendizaje del alumnado de ciencias del deporte. Revista Internacional de Medicina y Ciencias de la Actividad Física y del Deporte, v. 11, n. 41, p. 14-34, 2011.

SILVA, A. L. A auto-regulação da aprendizagem. In:

SILVA, A. L. et al. (Orgs.). Aprendizagem auto-regulada pelo estudante: perspectivas psicológicas e educacionais. Porto: Porto, 2004.

STEIN, S. J.; SHEPHARD, K.; HARRIS, I. Conceptions of e-learning and professional development for e-learning held by tertiary educators in New Zealand. British Journal of Educational Technology, v. 42, n. 1, p. 145-65, 2011. https://doi.org/10.1111/j.1467-8535.2009.00997.x

VALADAS, S. C. A. T.; GONÇALVES, F. R.; FAÍSCA, L. M. M. Perfis de aprendizagem de estudantes do ensino superior: Abordagens ao estudo, concepções de aprendizagem e preferências por diferentes tipos de ensino. Análise Psicológica, Lisboa, v. 29, n. 3, p. 369-89, 2011. 
YANG, Y.-F.; TSAI, C.-C. Conceptions of and approaches to learning through online peer assessment. Learning and Instruction, v. 20, n. 1, p. 72-83, 2010. https://doi.org/10.1016/j.learninstruc.2009.01.003

\section{Informações dos autores}

Luiz Gustavo Lima Freire: Mestre em Ciências da Educação e Doutor em Psicologia pela Universidade de Lisboa, Faculdade de Psicologia. Professor da Faculdade dos Guararapes. Contato: gstv.psi@gmail.com

(D) http://orcid.org/0000-0001-5898-0003

António Manuel Duarte: Doutor em Psicologia pela Universidade de Lisboa, Faculdade de Psicologia. Profesor Auxiliar da Universidade de Lisboa, Faculdade de Psicologia. Contato: amduarte@psicologia.ulisboa.pt

D http://orcid.org/0000-0002-9497-7204 